Article

\title{
Biomimicry: Do Frames of Inquiry Support Search and Identification of Biological Models?
}

\author{
Emily B. Kennedy * and Peter H. Niewiarowski \\ Department of Biology, The University of Akron, Akron, OH 44325, USA; phn@uakron.edu \\ * Correspondence: ekennedy@uakron.edu
}

Received: 16 May 2018; Accepted: 20 July 2018; Published: 30 July 2018

\begin{abstract}
A crucial step in the biomimicry process is the search and identification of biological models relevant to the design challenge. Anecdotal observations from case studies in authentic business contexts, as well as emerging literature on biomimicry methods, suggest that tools, which focus the search for biological models, could help research and development (R\&D) professionals execute this step more effectively. We prototyped one such tool, a set of four frames of inquiry, to test whether it helped R\&D professionals identify a greater quantity and variety of biological models. The tool we prototyped did not significantly improve biological model identification; however, its use was associated with a trend of higher quantity and variety of biological models. Our study, as well as previous work, both empirical and theoretical, suggests that tools, like ours, could improve the search and identification of biological models. We encourage further tests using larger samples sizes and/or conditions that maximize potential effect sizes.
\end{abstract}

Keywords: biomimicry; bioinspired design; front end innovation; new product development

\section{Introduction}

Biomimicry can be defined as innovation through emulation of biological forms, processes, patterns, and systems [1]. It is based on the idea that natural selection favors highly adapted and differentiated survival strategies that can be translated to address technical challenges. VELCRO ${ }^{\circledR}$, an adhesive system inspired by how burrs cling to animal fur, is an example of biomimicry [2]. Despite biomimicry's potential to deliver disruptive product innovations [3,4], and excellent reviews of existing methods and associated tools $[5,6]$, little has been published on best practices apart from a few studies carried out with students in classroom settings [7-17]. Notably absent in the literature are industry field studies designed to support and inform development of procedural scaffolding for the industry practice of biomimicry. This limits understanding and effective implementation in such contexts $[18,19]$. The purpose of this study is to begin to bridge this gap in the literature by providing practical, evidence-based recommendations for industry practitioners of biomimicry.

A biomimicry case study [3] provided motivation for the current study. The goal in the industry case was innovation of more energy-efficient, touch-free liquid soap and sanitizer dispensers. Consumers show preference for automatic, touch-free dispensing systems, which reduce direct transmission of germs versus manual, push bar systems, but require battery power. Biomimicry, as implemented in this industry case, generally comprised five iterative phases: (1) Problem definition; (2) specification of desired function(s); (3) identification of biological models exemplifying desired function(s); (4) extraction of design principles embodied by biological models; and (5) ideation of biomimicry-based solutions using design principles as the stimulus. The desired function specified for the liquid soap and sanitizer dispensing challenge was fluid distribution or transfer. Thus, "How do biological models distribute or transfer fluid?" was the research question participants in the industry case that motivated this study used to query biology. The breadth of this research question 
overwhelmed some project participants. Typically, these participants attempted to narrow their searches by generating and applying 'frames of inquiry' (Table 1), hereafter termed 'frames.' Frames can be understood as heuristics that tightened the field of view to make sifting through an expanse of biological information more manageable [3]. Implementing a narrower scope to facilitate identification of biological models in biomimicry is a behavior consistent with innovation research that suggests a brainstorming problem presented as a series of separate questions, versus one all-encompassing question, results in a greater quantity and variety of ideas because it refocuses attention more evenly across the entire problem [20]. Tools that direct focus during searches for analogous solutions in distant domains, like biology, have a particularly important role to play [21].

Table 1. Four frames of inquiry self-generated by research and development (R\&D) professionals practicing biomimicry. Adapted from [3]. Reprinted by permission of the Industrial Research Institute, www.iriweb.org.

\begin{tabular}{llll}
\hline \multicolumn{1}{c}{ Frame of Inquiry } & \multicolumn{1}{c}{ Assumption } & $\begin{array}{l}\text { Hypothetical } \\
\text { Challenge }\end{array}$ & Resulting Focus \\
\hline $\begin{array}{l}\text { Similar context: What biological } \\
\text { models exist in a context like the } \\
\text { problem context? }\end{array}$ & $\begin{array}{l}\text { Biological models inhabiting } \\
\text { environments like the problem } \\
\text { context will adopt strategies that } \\
\text { may be relevant to the problem. }\end{array}$ & Wet Adhesion & $\begin{array}{l}\text { Models that affix in wet } \\
\text { environments, like mussels }\end{array}$ \\
\hline $\begin{array}{l}\text { Extremes: What biological models } \\
\text { deal with extreme versions of } \\
\text { the problem? }\end{array}$ & $\begin{array}{l}\text { Biological models most } \\
\text { challenged by the problem will } \\
\text { embody the most robust strategies } \\
\text { for addressing it. }\end{array}$ & $\begin{array}{l}\text { Stormwater } \\
\text { Management }\end{array}$ & $\begin{array}{l}\text { Models living in regions with high } \\
\text { annual rainfall, like water } \\
\text { retaining sphagnum moss } \\
\text { growing on the rainforest floor }\end{array}$ \\
\hline $\begin{array}{l}\text { Convergence: What biological } \\
\text { strategy for accomplishing the } \\
\text { desired function is used by many, } \\
\text { distantly related species? }\end{array}$ & $\begin{array}{l}\text { A strategy independently evolved } \\
\text { in different contexts is likely to be } \\
\text { a beneficial approach. }\end{array}$ & $\begin{array}{l}\text { Location } \\
\text { Tracking }\end{array}$ & $\begin{array}{l}\text { Sonar-like echolocation, } \\
\text { independently evolved by bats, } \\
\text { toothed whales, and shrews }\end{array}$ \\
$\begin{array}{l}\text { Stasis: What biological strategy for } \\
\text { accomplishing the desired } \\
\text { function has persisted over time? }\end{array}$ & $\begin{array}{l}\text { A strategy that has been } \\
\text { conserved through evolution is } \\
\text { likely to be effective and difficult } \\
\text { for competitors to defeat. }\end{array}$ & $\begin{array}{l}\text { Dynamic } \\
\text { Buoyancy }\end{array}$ & $\begin{array}{l}\text { The chambered nautilus, a marine } \\
\text { mollusk whose form has remained } \\
\text { largely unchanged for } \\
\sim 400 \text { million years }\end{array}$ \\
\hline
\end{tabular}

Some of the frames generated by participants are traceable to biological model search recommendations made in biomimicry practitioner texts. For example, the Biomimicry Resource Handbook: A Seedbank of Best Practices encourages practitioners to focus their search for biological models "on contexts similar to the project's context", because strategies subject to the same operating conditions can be more readily applied [22]. This directive corresponds to the "similar context" frame (Table 1). The Biomimicry Resource Handbook also recommends that practitioners look for "organisms that are most challenged by the problem you are trying to solve, but remain unfazed by it" [22]. This directive corresponds to the "extremes" frame (Table 1). Support for remaining frames comes from various sources. For example, Yen et al. [17] provides a basis for our "convergence" frame (Table 1), asserting that "convergent evolution, where organisms from completely different lineages arrive at the same solution to similar conditions is one means to identify key biological mechanisms that may be useful for engineered design". Similarly, literature on "living fossils" provides a basis for our "stasis" frame (Table 1). As Worth and Shear [23] note, "a key innovation renders living fossils successful in persisting for long stretches of time", and, "just as wide-moat companies are good bets for investors seeking continued performance, living fossils yield strong long-term returns".

In biomimicry, frames function as practical discovery devices aimed at improving the search and identification of biological models among research and development (R\&D) professionals. Frames are not intended to capture the precise detail and complexity of the biological domain, and that is a dimension of their utility because it makes them accessible to non-biologists. Despite the application of frames during biomimicry [3], as well as their promotion in some practitioner texts, no study has yet investigated whether providing frames actually improves the search and identification of biological models relevant to a particular design challenge. Such evidence could be important since the 
identification of biological models exemplifying desired function(s) is a hurdle in biomimicry [24,25]. Other challenges include the resourcing of information about identified models $[3,26]$, selection of the most informative models from the initial collection [24], and scaling difficulties [24]. The identification of biological models is the focus in this study as it is nearest the front end of the biomimicry process. The front end is regarded as one of the biggest opportunity areas for improving an innovation process [27]. Specifically, we investigate:

a. Capacity for identifying biological models: We hypothesized that the quantity and variety of biological models identified would be greater for teams provided the four frames outlined in Table 1 compared to teams not provided with the frames;

b. frames cited: We hypothesized that: (1) the variance in the number of frame citations among teams provided frames would be influenced by the assigned search objective, suggesting the usefulness of frames is problem-dependent, and that (2) certain frames would be cited more often than others, potentially indicating greater utility;

c. influence of demographics: We explored whether variation in several demographic factors was associated with team results and individual perceptions about the exercise.

\section{Materials and Methods}

A study of 91 R\&D professionals and summer interns was conducted on 15 July 2015, at the Akron Zoo (Akron, OH, USA) during the participating company's annual offsite R\&D department teambuilding event. The 50-acre Akron Zoo is home to over 700 animals and 7000 plants and flowers. Attendees $(n=91)$ were familiarized with the concept of biomimicry via a 30-min introductory presentation delivered by one of the study's authors, then were randomly assigned by event organizers to one of 12 seven- or eight-person teams, the average size of working groups at the participating company. Six of the 12 teams were instructed to 'search and identify biological models for attachment, including temporary attachment and attachment to irregular surfaces' (Search Objective 1). Resulting biological models were expected to be relevant to the innovation of versatile mounting brackets for soap and sanitizer dispensers. 'Biological model' was defined for participants as any subcellular to macroecological scale form, process, or system, and, therefore, inclusive of organismal subsystems, organisms, and superorganisms. Each team was provided a map of the zoo grounds and assigned a process coach who received verbal and written instruction on how to keep the team on task throughout the exercise (Table 2).

Table 2. Process coach instructions.

\begin{tabular}{cl}
\hline No. & \multicolumn{1}{c}{ Instruction } \\
\hline 1 & $\begin{array}{l}\text { Remind team, as necessary, that they have been instructed to identify and record in legible } \\
\text { handwriting as many biological models as possible. }\end{array}$ \\
\hline 2 & Remind team, as necessary, to visit as many exhibits as possible. \\
\hline 3 & Remind team, as necessary, that a 'biological model' includes biological organisms from all kingdoms. \\
\hline 4 & Remind team, as necessary, that they should not discuss their handout outside their team. \\
\hline 5 & Encourage all team members to participate. \\
\hline 7 & Do not identify biological models for the team. \\
\hline 8 & Wrap at 60 min and collect completed handouts. \\
\hline 10 & $\begin{array}{l}\text { Lead your team to the picnic area where you will provide a survey to everyone on your team and ask } \\
\text { them to complete it. }\end{array}$ \\
\hline
\end{tabular}


Teams spent 60 min exploring the zoo grounds with their process coach, searching and identifying biological models relevant to their assigned search objective. Prior to being dispatched, three of the six teams assigned to Search Objective 1 and three of the six teams assigned to Search Objective 2, were given copies (two per team) of Handout 1 (Appendix A). This handout instructed participants to search and identify as many biological models as they could within the allotted 60 min guided by the basic biomimicry research question, "How do biological models accomplish the desired function(s)?" These teams represent the control group. Remaining teams were given copies (two per team) of Handout 2 (Appendix B). This handout instructed participants to search and identify as many biological models as possible within the allotted $60 \mathrm{~min}$ guided by the frames. These participants were further instructed to code each biological model by which frame helped lead to its identification. These teams represent the experimental group (Table 3). The purpose of providing each team with two copies of their respective handouts was to allow for two people to simultaneously record data and provide ample space. A single copy of Handout 1 or Handout 2 provides space for recording 12 biological models. Across two copies each team had space to record 24 models, a number that well exceeded the total researchers expected any team to identify in $60 \mathrm{~min}$.

Table 3. Experimental design matrix.

\begin{tabular}{ccc}
\hline Handout & Search Objective 1 & Search Objective 2 \\
\hline 1 (control) & 3 teams & 3 teams \\
2 (experimental) & 3 teams & 3 teams \\
\hline
\end{tabular}

The process coach, in addition to keeping his or her team on task, simultaneously filled the role of observer during the 60-min search period, recording observations of group behavior. Process coaches were instructed to record anything deemed noteworthy, paying particular attention to: (1) Any observed use of smartphones (counter to instructions); (2) any observed discussion of handouts with other teams (counter to instructions); (3) instances in which their team was within earshot of another and could have overheard ideas; (4) any observed power relationships that may have inhibited openness or participation of some team members; and (5) for teams in the experimental group, the extent to which a vocal group leader may have unduly influenced how much time was spent considering each frame. These observations were collected as a means of disqualifying erroneous data.

After $60 \mathrm{~min}$, all teams congregated at the Akron Zoo's picnic area and submitted their completed handouts. Then, individuals were asked to complete one of two anonymous surveys depending on whether their team was provided with frames or not. Individuals from teams in the control group (no frames) were administered Survey 1 (Appendix C). Individuals from teams in the experimental group (frames) were administered Survey 2 (Appendix D). The surveys asked individuals about their gender, age, educational attainment, disciplinary background, assigned search objective, level of familiarity with biomimicry, and perceived difficulty of the exercise. The survey provided to individuals from teams in the experimental group also asked what other frames of inquiry, in addition to the four provided, might support search and identification of biological models. Individuals submitted their completed surveys and a brief group discussion followed. Participants were informed of the differences between the control and experimental treatments, and asked: What do you think was the impact of providing frames to some groups?

Completed handouts, process coach observations, survey responses, and audio recording of the brief group discussion comprise the quantitative and qualitative data analyzed to investigate the quantity and variety of models generated, frames cited, and the influence of demographics. All statistical analyses were performed using JMP ${ }^{\circledR}$ Pro 13.2 software (SAS Institute, Cary, NC, USA). We used ANOVA when testing if the means differed between the control and experimental groups (i.e., quantity of models generated, variety of models generated, and perceived difficulty of the exercise), and a chi-squared test to compare the distribution of frames cited between experimental groups assigned to different search objectives. Finally, we explored the influence of demographic variables 
(e.g., gender, age, educational background) on participants' qualitative perceptions about the exercise by performing a mixed model ANOVA, with the group treated as a random factor. The normality of the residuals was checked and confirmed prior to analysis for all ANOVAs using the Shapiro-Wilk statistic.

\section{Results}

Process coaches observed teams adhering to instructions. Teams did not use smartphones or discuss the content of handouts with other teams. There were instances in which teams crossed paths between exhibits, but no two teams ever occupied the same exhibit. Thus, while overhearing another team's ideas was possible, we believe any effect is negligible. With process coach encouragement, there was reasonably balanced team member participation with no single, dominant voice on any team. Therefore, no data were disqualified as being obviously biased.

\subsection{Capacity for Identifying Biological Models}

The control group (no frames) produced an average of 15.5 biological models per team, compared to 17.8 for the experimental group (frames). Search objective and the search objective by frames interaction were not significant, so we pooled across search objectives and determined that the control and experimental group did not differ statistically in terms of the quantity of biological models generated (ANOVA $F_{1,10}=0.39, p=0.54$ ). Variation among teams in the number of biological models produced was greater for the experimental $(\mathrm{SD}=7.9)$ versus the control group $(\mathrm{SD}=4.5)$, but was not significantly different (Bartlett test, $p=0.25$ ). The variety of proposed biological models, in terms of number of phyla represented, was greater for the experimental $(6.2, \mathrm{SD}=0.94)$ versus the control group $(5.0, \mathrm{SD}=0.94)$, but was not significantly different (ANOVA $F_{1,10}=0.77, p=0.40$ ).

\subsection{Frames Cited}

Within the experimental group, the total citations per frames 1, 2, 3, and 4 were 31, 14, 20, and 31, respectively. Based on a review of the completed handouts, frames were not coded in any particular order. While the average number of frame citations for teams in the experimental group assigned to Search Objective $1(22, \mathrm{SD}=5)$ was nearly twice as large as for teams assigned to Search Objective 2 $(10, \mathrm{SD}=8.72)$, this difference was not statistically significant (ANOVA, $\left.F_{1,4}=4.3, p>0.108\right)$ due to a small sample size and large within group variance. Also, the number of frame citations among teams in the experimental group did not vary significantly as a function of the specific frame, assigned search objective, or the interaction (ANOVA, $F_{7,16}=0.8243, p>0.582$ ). However, the number of different frames used was significantly positively related to the total number of biological models generated $\left(r^{2}=0.58, p=0.049\right)$. Teams who were provided with the four frames differed in the frequency that different frames were adopted to identify biological models $\left(\chi^{2}{ }_{12,96}=50.1, p<0.001\right)$.

\subsection{Influence of Demographics}

Participants' perception about the difficulty of the exercise, as reflected on a five-point Likert scale ( $1=$ Very difficult, $5=$ Very easy $)$, was not related to whether they were in the control or experimental group (3.3 vs. 3.0 respectively; ANOVA $F_{1,9}=1.9, p=0.20$ ). Moreover, demographic traits, including age, educational attainment (possession of a college degree), and disciplinary background, did not influence the perceived difficulty, but gender did, with males $(n=56)$ reporting having less difficulty with the exercise than females $(n=34)$ (3.4 vs. 3.0; ANOVA $\left.F_{1,67}=5.9, p=0.02\right)$ irrespective of whether they were in the control or experimental group. A participant's prior familiarity with biomimicry, as reflected on a five-point Likert scale ( $1=$ Not at all familiar, $5=$ Extremely familiar), was not related to their perception of the difficulty of the exercise (mean familiarity $=3.1$; mean perceived difficulty $=3.2$ ) for either the control $(p>0.78)$ or the experimental group $(p>0.21)$. Table 4 summarizes notable quantitative results. 
Table 4. Summary of select quantitative results.

\begin{tabular}{lcc}
\hline \multicolumn{1}{c}{ Effect } & \multicolumn{1}{c}{ Description } \\
\hline $\begin{array}{l}\text { Average number of biological models generated (quantity). } \\
\text { Greater for frames, but not significantly different. }\end{array}$ & $\begin{array}{c}17.8 \text { models per team } \\
\text { (frames) }\end{array}$ & $\begin{array}{c}15.5 \text { models per team } \\
\text { (no frames) }\end{array}$ \\
\hline $\begin{array}{l}\text { Average number of phyla represented by biological } \\
\text { models generated (variety). Greater for frames, but not } \\
\text { significantly different. }\end{array}$ & $\begin{array}{c}\text { 6.2 phyla per team } \\
\text { (frames) }\end{array}$ & $\begin{array}{c}5.0 \text { phyla per team } \\
\text { (no frames) }\end{array}$ \\
\hline $\begin{array}{l}\text { Within the experimental group, average number of frame } \\
\text { citations. Greater for Search Objective 1, but not } \\
\text { significantly different. }\end{array}$ & $\begin{array}{c}\text { 22 citations } \\
\text { Relationship }\end{array}$ & $\begin{array}{c}\text { 10 citations } \\
\text { (Search Objective 2) }\end{array}$ \\
\hline $\begin{array}{l}\text { Within the experimental group, number of different frames }) \\
\text { cited vs. number of biological models generated. }\end{array}$ & Description \\
\hline $\begin{array}{l}\text { Perceived difficulty of the exercise as reflected on a } \\
\text { five-point Likert scale (1 = Very Difficult, } 5=\text { Very Easy). }\end{array}$ & $\begin{array}{c}\text { Men find the exercise easier }(3.4) \text { than women } \\
\text { (3.0): ANOVA } F_{1,67}=5.9, p=0.02\end{array}$ \\
\hline
\end{tabular}

\section{Discussion}

Although, on average, teams provided with frames identified a greater quantity and variety of biological models, neither difference was statistically significant. These results ran counter to our hypothesis that frames would increase the number and variety of biological models identified. It is important to note that even though the scale of the experiment was reasonably large, the power to test this hypothesis was low $(10 \%)$. The low statistical power arose from a combination of a small effect of frames and high variance among groups within treatments. Because there is very little comparable, pre- existing work, the low power arising from inadequate sample size, and/or other aspects of our experimental design and execution, was unexpected. Nevertheless, in an emerging field like biomimicry, our negative results serve as a substantive reference point for the design of future industry field studies. Variance among groups might be reduced in several ways to potentially lead to a clearer or stronger impact of frames. For example, high among group variance for teams given frames may have arisen because the effect of frames is complex. Our survey results, process coach observations, and comments made during the brief group discussion suggest that in a zoo environment the provision of frames helps some R\&D professionals search and identify a greater quantity of biological models, and impedes others, at least in the near term, as they spend time comprehending frames. Indeed, some participants said the frames helped them determine "what exhibits to visit and what to look for in those exhibits", while others found the frames "confusing", and "had to consume part of their allotted 60 min making sense of them". One of the process coaches assigned to a team in the experimental group observed his team "taking a considerable amount of time to read instructions", while another described an "initial struggle to understand the convergence frame". One way to modify the design of our experiment would be to have participants in the experimental group exposed to the frames prior to the timed exercise or receive in-advance training in how to use frames. Alternately, a follow-up study might investigate the effect of a single frame at a time to reduce comprehension challenges for participants assigned to the experimental group. Anticipation of comprehensive complexity may be why texts that offer support for the implementation of frames for search and identification of biological models present only one or two frames per publication $[17,22,23]$.

Interestingly, the number of different frames used by teams in the experimental group was significantly positively related to the total number of biological models generated. The four frames provided to teams in the experimental group may be complimentary in that each led R\&D professionals to different biological models. A set of complimentary frames compiled from the literature $[3,17,22,23,28]$ and expanded upon could result in a significant positive effect of providing frames on the quantity of biological models generated. Survey 2 , administered to individuals in the 
experimental group, asked what other frames of inquiry (in addition to those provided) might support search and identification of biological models. Some of the responses provide a basis for an expanded set of potentially complimentary frames:

- "A frame that encourages consideration of how a species evolved over time; what features changed and in what way to advance a solution? What is the trajectory for future change?"

- "A frame that encourages search for the exact opposite behavior (e.g., repulsion instead of adhesion)"

- "A frame that considers opposition in nature-how do predators overcome evolved solutions?"

During the brief group discussion that followed the exercise, one participant expressed her opinion that "the frames of inquiry were unnecessary in a stimulus-rich environment like the zoo". This participant added that "in a different context, like a stark conference room, the frames may have been more useful". Echoing this sentiment, another participant suggested frames "would be more helpful to push a search for biological models further after all the obvious models have been identified". Based on these comments, the value of frames for facilitating search and identification of analogous solutions in biology might depend on the richness of the search context or could be more beneficial, regardless of context, when introduced partway through a search after more obvious models have been identified.

Irrespective of whether they were in the control or experimental group, males perceived the biomimicry exercise to be significantly easier than females. Educational studies have discovered negative correlations between the perceived task difficulty and level of interest [29,30]. It follows that female participants, who reported having significantly more difficulty with the biomimicry exercise, may have been less interested by it. Supposing this is true, it would conflict with existing evidence that biomimicry, an approach to environmentally sustainable product innovation $[3,4]$, attracts underrepresented female populations to science, technology, engineering, and math (STEM). Previous studies have found sustainability-themed design projects are disproportionately appealing to women [31,32], and can increase women's confidence in engineering problem-solving [31]. Women are drawn to programs and initiatives that link science, technology, and engineering to real world applications, showing how engineering principles can be applied to solve problems, thereby improving people's lives [33-36]. As an applied design science, biomimicry emphasizes this link.

\section{Conclusions}

The goal of this field-based study was to answer the following question: In the industry practice of biomimicry, do frames of inquiry support the search and identification of biological models? Our study did not find significant positive effects of frames on the quantity or variety of biological models generated. It may be that there is, indeed, no effect of the experimental treatment. While the scale of our study was arguably large for the context in which we were working, it remains to be seen if further testing of the effectiveness of frames in a way that accounts for the relatively small effect size and/or high variance is warranted. There are very few biomimicry studies conducted in industrial settings, even though the results of such studies might be more compelling to corporate R\&D teams than studies conducted in academic settings with students. Indeed, our own anecdotal experience suggests that corporate R\&D teams are interested in biomimicry, but potentially discouraged from implementing it given the shortage of definitive industry-based studies elucidating best practices. Business professionals are an understudied population requiring research attention [37]. It is far more common to assess innovation techniques with student participants in a classroom setting [38] because students, and undergraduates in particular, are readily accessible, abundant, and tend to be receptive to complex experimental designs [39]. In many fields, the results of experiments using student participants are assumed to be generalizable [37]; but innovation is especially sensitive to the influence of context and life experience [39]. In this field, experimental findings based on student behaviors in classroom settings are less likely to be generalizable for business application [40]. 
Undergraduates are distinct from business professionals because, at an average of 18-22 years old, they tend to lack crystallized attitudes [41], have limited firsthand experience of corporate culture, and without domain expertise are not privy to existing solutions. (Some of our study participants were undergraduates interning at the participating company during the summer break, but by 15 July 2015, they were fully onboarded, with at least two months' experience with the company. They participated in this study in their capacity as interns, versus students, in a real, versus simulated, business environment.) Collecting data in a corporate environment, through face-to-face conversation and behavioral observation, at the site where participants experience the phenomenon under study, lends credibility to the findings [42-45]. So, how do we design studies with business professionals that do generate statistically significant results and encourage widespread adoption of biomimicry?

This study offers insight by revealing that the industrial research context may require larger sample sizes and/or conditions that maximize potential effect sizes to provide results that are interpretable. These insights can contribute to how scholars and practitioners continue to develop biomimicry best practices in contexts other than the classroom. A follow on to this study could double the sample size and reduce variance in the effect of frames by using a single search objective instead of two. A follow on might also reduce and refine the number of frames offered as a way of reducing variance in the effect of frames as compared to no frames. While authentic R\&D sessions may not provide ideal platforms for maximizing sample size and controlling sources of variance while isolating a few experimental effects, we believe our results warrant further exploration. Studies in an authentic business context could significantly advance both practice and theory in the emerging and rapidly expanding field of biomimicry [46].

Author Contributions: Conceptualization, E.B.K. and P.H.N.; Data curation, P.H.N.; Formal analysis, P.H.N.; Investigation, E.B.K. and P.H.N.; Methodology, E.B.K. and P.H.N.; Project administration, E.B.K.; Resources, E.B.K. and P.H.N.; Supervision, E.B.K. and P.H.N.; Validation, E.B.K. and P.H.N.; Writing-original draft, E.B.K.; Writing-review \& editing, E.B.K. and P.H.N.

Funding: This research received no external funding.

Acknowledgments: The authors thank Adam Pierce, Matthew Kolodziej, Sebastian Engelhardt, Kelly Siman, Torrey McMillan, Michael Wilson, Trisha Brown, Carol Thaler, and Bill Hsiung for process coaching, as well as Nick Ciavarella and Petra Gruber for providing feedback on earlier drafts of this manuscript.

Conflicts of Interest: The authors declare no conflict of interest.

\section{Appendix A. Handout 1 (2 Versions for 2 Search Objectives)}

\section{Handout 1-Search Objective 1}

Search and identify as many biological models for attachment, including temporary attachment and attachment to irregular surfaces, as you can within the allotted $60 \mathrm{~min}$. Your search should be guided by the question:

"How do biological models accomplish the desired function(s)?"

\begin{tabular}{ll}
\hline Biological Model & Details \\
Subcellular to macroecological scale / Form, process, or system & How is this biological model relevant to your search objective? \\
\hline+11 rows for 12 rows total & \\
\hline
\end{tabular}

\section{Handout 1-Search Objective 2}

Search and identify as many biological models for sealed storage/liquid containment as you can within the allotted $60 \mathrm{~min}$. Your search should be guided by the question:

"How do biological models accomplish the desired function(s)?"

Biological Model

Subcellular to macroecological scale / Form, process, or system

+11 rows for 12 rows total
Details

How is this biological model relevant to your search objective? 


\section{Appendix B. Handout 2 (2 Versions for 2 Search Objectives)}

(Front)

\section{Handout 2-Search Objective 1}

Search and identify as many biological models for attachment, including temporary attachment and attachment to irregular surfaces, as you can within the allotted $60 \mathrm{~min}$. Your search should be guided by the frames of inquiry listed on the reverse side of this handout. Code each biological model according to which frame of inquiry helped lead to its identification.

\begin{tabular}{lll}
\hline Biological Model & Details & Frame of Inquiry Code \\
$\begin{array}{l}\text { Subcellular to macroecological scale / Form, } \\
\text { process, or system }\end{array}$ & $\begin{array}{l}\text { How is this biological model relevant to } \\
\text { your search objective? }\end{array}$ & $\begin{array}{l}\text { (F1, F2, F3, F4) } \\
+11 \text { rows for 12 rows total }\end{array}$ \\
\hline
\end{tabular}

\section{Handout 2-Search Objective 2}

Search and identify as many biological models for sealed storage/liquid containment as you can within the allotted $60 \mathrm{~min}$. Your search should be guided by the frames of inquiry listed on the reverse side of this handout. Code each biological model according to which frame of inquiry helped lead to its identification.

\begin{tabular}{|c|c|c|}
\hline $\begin{array}{l}\text { Biological Model } \\
\text { Subcellular to macroecological scale / Form, } \\
\text { process, or system }\end{array}$ & $\begin{array}{l}\text { Details } \\
\text { How is this biological model relevant to } \\
\text { your search objective? }\end{array}$ & $\begin{array}{l}\text { Frame of Inquiry Code } \\
(F 1, F 2, F 3, F 4)\end{array}$ \\
\hline+11 rows for 12 rows total & & \\
\hline
\end{tabular}

(Back)

\section{Frames of Inquiry}

F1: Similar Context-What biological models exist in a context like the problem context in terms of scale of interest, climate, etc.? (This frame assumes biological models inhabiting environments like the problem context will adopt strategies that may be relevant to the problem.)

Example: If the desired function was wet adhesion, an innovator adopting a "similar context" frame of inquiry would search and identify models that affix in wet environments (i.e., mussels).

F2: Extremes-What biological models deal with the extreme versions of the problem? (This frame assumes biological models most challenged by the problem will embody the most robust strategies for addressing it.)

Example: If the desired function was stormwater management, an innovator adopting an "extremes" frame of inquiry would search and identify models living in regions with high annual rainfall (i.e., water retaining sphagnum moss growing on the rainforest floor).

F3: Convergence-What biological strategy for accomplishing the desired function is used by many, distantly related species? (This frame assumes a strategy independently evolved in different contexts is likely to be a beneficial approach.)

Example: If the desired function was location tracking, an innovator adopting a "convergence" frame of inquiry would be particularly interested in sonar-like echolocation, independently evolved by bats, toothed whales, and shrews.

F4: Stasis-What biological strategy for accomplishing the desired function has persisted over time? (This frame assumes a strategy that has been conserved through evolution is likely to be effective and difficult for competitors to defeat.) 
Example: If the desired functions was dynamic buoyance, an innovator adopting a "stasis" frame of inquiry would be particularly interested in the chambered nautilus, a marine mollusk whose form has remained largely unchanged for $\sim 400$ million years.

\section{Appendix C. Survey 1}

1. What is your gender? Check a box.
$\square$ Male
$\square$ Female
$\square$ I prefer not to specify

2. What is your age? Check a box.
$\square 17$ years and under
$\square$ 18-29 years old
$\square$ 30-49 years old
$\square$ 50-64 years old
$\square 65$ years and over

3. What is the highest level of education you have attained? Check a box.

$\square$ Some high school

$\square$ High school graduate

$\square$ Some college

$\square$ Trade/technical/vocational training

$\square$ College graduate

$\square$ Some postgraduate work

$\square$ Post graduate degree

4. I earned a college/postgraduate degree(s) in the following subject area(s):

Leave blank if none.

5. To which search objective was your team assigned?

$\square$ Search Objective 1-Search and identify biological models for attachment, including temporary attachment and attachment to irregular surfaces

Search Objective 2-Search and identify biological models for sealed storage/liquid containment

6. What is your level of familiarity with biomimicry? Circle a number.

$\begin{array}{ccccc}\text { Not at all familiar } & \text { Slightly familiar } & \text { Somewhat familiar } & \text { Moderately familiar } & \text { Extremely familiar }\end{array}$

7. How difficult did you find this exercise? Circle a number.

Very difficult

1

Difficult

2
Neutral

3

Easy
4

Very easy

5

\section{Appendix D. Survey 2}

Same Qs \#1-7 as Survey 1 (Appendix C) + 
8. What other frames of inquiry (in addition to those provided) might support search and identification of biological models?

\section{References}

1. Benyus, J.M. Spreading the Meme: A Biomimicry Primer. In Biomimicry Resource Handbook: A Seed Bank of Best Practices; CreateSpace Independent Publishing Platform: Scotts Valley, CA, USA, 2013.

2. Jenkins, C.H. Bio-Inspired Engineering; Momentum Press: New York, NY, USA, 2012.

3. Kennedy, E.B.; Marting, T.A. Biomimicry: Streamlining the Front End of Innovation for Environmentally Sustainable Products. Res. Technol. Manag. 2016, 59, 40-48. [CrossRef]

4. Lurie-Luke, E. Product and technology innovation: What can biomimicry inspire? Biotechnol. Adv. 2014, 32, 1494-1505. [CrossRef] [PubMed]

5. Fayemi, P.E.; Wanieck, K.; Zollfrank, C.; Maranzana, N.; Aoussat, A. Biomimetics: Process, tools and practice. Bioinspir. Biomim. 2017, 12, 011002. [CrossRef] [PubMed]

6. Wanieck, K.; Fayemi, P.-E.; Maranzana, N.; Zollfrank, C.; Jacobs, S. Biomimetics and its tools. Bioinspired Biomim. Nanobiomater. 2017, 6, 53-66. [CrossRef]

7. Farel, R.; Yannou, B. Bio-inspired ideation: Lessons from teaching design to engineering students. In Proceedings of the 19th International Conference on Engineering Design, Seoul, Korea, August 2013; pp. 327-336.

8. Glier, M.W.; McAdams, D.A.; Linsey, J.S. Concepts in biomimetic design: methods and tools to incorporate into a biomimetic design course. In Proceedings of the ASME 2011 International Design Engineering Technical Conferences \& Computers and Information in Engineering Conference, Washington, D.C., USA, August 2011; pp. 1-6.

9. Goel, A.K.; Zhang, G.; Wiltgen, B.; Zhang, Y.; Vattam, S.; Yen, J. On the benefits of digital libraries of case studies of analogical design: Documentation, access, analysis, and learning. Artif. Intell. Eng. Des. Anal. Manuf. 2015, 29, 215-227. [CrossRef]

10. Goel, A.K.; Vattam, S.; Wiltgen, B.; Helms, M. Cognitive, collaborative, conceptual and creative-Four characteristics of the next generation of knowledge-based CAD systems: A study in biologically inspired design. Comput. Aided Des. 2012, 44, 879-900. [CrossRef]

11. Helms, M.; Vattam, S.S.; Goel, A.K. Biologically inspired design: Process and products. Des. Stud. 2009, 30, 606-622. [CrossRef]

12. Nagel, J.K.S.; Nagel, R.L.; Eggermont, M. Teaching biomimicry with an engineering-to-biology thesaurus. In Proceedings of the ASME 2013 International Design Engineering Technical Conferences \& Computers and Information in Engineering Conference, Portland, OR, USA, August 2013; pp. 1-10.

13. Nagel, J.K.S.; Pidaparti, R.M. Significance, prevalence and implications for bio-inspired design courses in the undergraduate engineering curriculum. In Proceedings of the ASME 2015 International Design Engineering Technical Conferences \& Computers and Information in Engineering Conference, Charlotte, NC, USA, August 2016; pp. 1-10.

14. Nagel, J.K.S.; Pittman, P.L.; Pidaparti, R.; Rose, C.S.; Beverly, C.L. Teaching bio-inspired design using C-K theory. Bioinspired Biomim. Nanobiomater. 2017, 6, 77-86. [CrossRef]

15. Nelson, B.; Wilson, J.; Yen, J. A study of biologically-inspired design as a context for enhancing student innovation. In Proceedings of the 39th ASEE/IEEE Frontiers in Education Conference, San Antonio, TX, USA, October 2009; pp. 1-5.

16. Wilson, J.O.; Rosen, D.; Nelson, B.A.; Yen, J. The effects of biological examples in idea generation. Des. Stud. 2010, 31, 169-186. [CrossRef]

17. Yen, J.; Helms, M.; Vattam, S.S.; Goel, A.K. Evaluating biological systems for their potential in engineering design. Adva. Nat. Sci. 2010, 3, 27-40.

18. Nagel, J.K.S.; Stone, R.B. A computational approach to biologically inspired design. Artif. Intell. Eng. Des. Anal. Manuf. 2012, 26, 161-176. [CrossRef]

19. Vincent, J.F.V.; Bogatyreva, O.A.; Bogatyrev, N.R.; Bowyer, A.; Pahl, A.-K. Biomimetics: Its practice and theory. J. R. Soc. Interface 2006, 3, 471-482. [CrossRef] [PubMed] 
20. Dennis, A.R.; Valacich, J.S.; Connolly, T.; Wynne, B.E. Process structuring in electronic brainstorming. Inf. Syst. Res. 1996, 7, 268-277. [CrossRef]

21. Linsey, J.S.; Wood, K.L.; Markman, A.B. Increasing innovation: Presentation and evaluation of the wordtree design-by-analogy method. In Proceedings of the ASME 2008 International Design Engineering Technical Conferences and Computers and Information in Engineering Conference, New York, NY, USA, August 2008; pp. 21-32.

22. Baumeister, D. Biomimicry Resource Handbook: A Seed Bank of Best Practices; CreateSpace Independent Publishing Platform: Missoula, MT, USA, 2014.

23. Werth, A.J.; Shear, W.A. The Evolutionary Truth about Living Fossils. Am. Sci. 2014, 102, 434-443.

24. Badarnah, L.; Kadri, U. A methodology for the generation of biomimetic design concepts. Archit. Sci. Rev. 2015, 58, 120-133. [CrossRef]

25. Vandevenne, D.; Pieters, T.; Duflou, J.R. Enhancing novelty with knowledge-based support for Biologically-Inspired Design. Des. Stud. 2016, 46, 152-173. [CrossRef]

26. Zari, M.P. Biomimetic approaches to architectural design for increased sustainability. In Proceedings of the New Zealand Sustainable Building Conference 2007, Auckland, New Zealand, November 2007; p. 033.

27. Koen, P.A.; Ajamian, G.M.; Boyce, S.; Clamen, A.; Fisher, E. Fuzzy front end: Effective methods, tools, and techniques. PDMA Toolbook New Prod. 2002, 1, 5-35.

28. Lenau, T.A.; Metze, A.-L.; Hesselberg, T. Paradigms for biologically inspired design. SPIE 2018, 10593, 1059302.

29. Tanaka, A.; Murayama, K. Within-Person Analyses of Situational Interest and Boredom: Interactions Between Task-Specific Perceptions and Achievement Goals. J. Educ. Psychol. 2014, 106, 1122-1134. [CrossRef]

30. Li, W.; Lee, A.; Solmon, M. The role of perceptions of task difficulty in relation to self-perceptions of ability, intrinsic value, attainment value, and performance. Eur. Phys. Educ. Rev. 2008, 14, 179-201. [CrossRef]

31. Oehlberg, L.; Shelby, R.; Agogino, A. Sustainable Product Design: Designing for Diversity in Engineering Education. Int. J. Eng. Educ. 2010, 26, 489-498.

32. Zimmerman, J.B.; Vanegas, J. Using Sustainability Education to Enable the Increase of Diversity in Science, Engineering and Technology-Related Disciplines. Int. J. Eng. Educ. 2007, 23, 242-253.

33. Busch-Vishniac, I.J.; Jarosz, J.P. Can diversity in the undergraduate engineering population be enhanced through curricular change? J. Women Minor. Sci. Eng. 2004, 10, 255-281. [CrossRef]

34. Koppel, N.B.; Cano, R.M.; Heyman, S.B. An Attractive Engineering Option for Girls. In Proceedings of the 32nd Annual Frontiers in Education, IEEE, Boston, MA, USA, November 2002; pp. F1C-2-F1C-7.

35. Mihelcic, J.R.; Paterson, K.G.; Phillips, L.G.; Zhang, Q.; Watkins, D.W.; Barkdoll, B.D.; Fuchs, V.J.; Fry, L.M.; Hokanson, D.R. Educating engineers in the sustainable futures model with a global perspective. Civ. Eng. Environ. Syst. 2008, 25, 255-263. [CrossRef]

36. Rhoten, D.; Pfirman, S. Women in interdisciplinary science: Exploring preferences and consequences. Res. Policy 2007, 36, 56-75. [CrossRef]

37. Druckman, J.M.; Kam, C.D. Students as Experimental Participants: A Defense of the 'Narrow Data Base; Cambridge University Press: Cambridge, UK, 2009.

38. Kilgour, M.; Koslow, S. Why and how do creative thinking techniques work? Trading off originality and appropriateness to make more creative advertising. J. Acad. Mark. Sci. 2009, 37, 298-309. [CrossRef]

39. Bello, D.; Leung, K.; Radebaugh, L.; Tung, R.L.; van Witteloostuijn, A. From the Editors: Student Samples in International Business Research. J. Int. Bus. Stud. 2009, 40, 361-364. [CrossRef]

40. Sears, D.O. College sophomores in the laboratory: Influences of a narrow data base on social psychology's view of human nature. J. Pers. Soc. Psychol. 1986, 51, 515. [CrossRef]

41. Henrich, J.; Heine, S.J.; Norenzayan, A. The weirdest people in the world? Behav. Brain Sci. 2010, 33, 61-83. [CrossRef] [PubMed]

42. Creswell, J.W.; Hanson, W.E.; Plano, V.L.C.; Morales, A. Qualitative Research Designs: Selection and Implementation. Couns. Psychol. 2007, 35, 236-264. [CrossRef]

43. Denzin, N.K.; Lincoln, Y.S. (Eds.) The Sage Handbook of Qualitative Research, 4th ed.; Sage: Thousand Oaks, CA, USA, 2011.

44. LeCompte, M.D.; Schensul, J.J. Designing \& Conducting Ethnographic Research; AltaMira Press: Walnut Creek, CA, USA, 1999. 
45. Marshall, C.; Rossman, G.B. Designing Qualitative Research, 5th ed.; Sage: Thousand Oaks, CA, USA, 2011.

46. Fermanian Business \& Economic Institute. Bioinspiration: An Economic Progress Report; San Diego Zoo \& Point Loma Nazarene University: San Diego, CA, USA, 2013.

(c)

(C) 2018 by the authors. Licensee MDPI, Basel, Switzerland. This article is an open access article distributed under the terms and conditions of the Creative Commons Attribution (CC BY) license (http:/ / creativecommons.org/licenses/by/4.0/). 